\title{
Ensino de matemática ou matemática do ensino? (Des)construções curriculares para a formação inicial de professores
}

\author{
Wagner Rodrigues Valente ${ }^{1}$ \\ Universidade Federal de São Paulo - UNIFESP
}

\begin{abstract}
RESUMO
A partir da temática "(Des)construções curriculares para a formação inicial de professores que ensinam matemática: desafios e cenários de possibilidades para (re)existir", este texto tem por objetivo promover uma reflexão sobre as possibilidades de (des)construção curricular para a formação inicial de professores que ensinam matemática, a partir de resultados de pesquisas históricas. Esses resultados mostram-nos a importância teórica de distinguir "ensino de matemática" e "matemática do ensino", em termos do ensino e da formação de professores. Com tal distinção e ancorado em bases teórico-metodológicas vindas da História Cultural, o estudo conclui que as possibilidades de (des)construção curricular passam pela mudança de natureza do saber a ser socializado pelo campo da Educação Matemática, caracterizado pela matemática do ensino.
\end{abstract}

Palavras-chave: Matemática; Campo disciplinar; Ensino de matemática; Educação Matemática; Epistemologia.

\section{Mathematics Teaching or Mathematics of Teaching? (Un)constructions of curricula for initial teacher training}

\begin{abstract}
From the theme "(Un)constructions of curricula for the initial training of teachers who teach mathematics: challenges and scenarios of possibilities for (re)existing", this text aims to promote a reflection on the possibilities of (un)constructing curricula for the initial training of teachers who teach mathematics from historical research results. These results show us the theoretical importance of distinguishing "mathematics teaching" and "mathematics of teaching", in terms of teaching and teacher training. With such distinction and anchored in theoretical and methodological bases coming from Cultural History, the study concludes that the possibilities of curricular (de)construction pass through the change of nature of knowledge to be socialized by the field of Mathematics Education, characterized by the mathematics of teaching.
\end{abstract}

Keywords: Mathematics; Disciplinary field; Mathematics teaching; Mathematics Education; Epistemology.

1 Professor Livre Docente (UNIFESP). Professor Associado do Departamento de Educação da UNIFESP/Campus Guarulhos, SP, Brasil. Endereço para correspondência: Estrada do Caminho Velho, 333 - Jd. Nova Cidade - Guarulhos SP - CEP: 07252-312. ORCID: http://orcid.org/0000-0002-2477-6677. E-mail: ghemat.contato@gmail.com 


\title{
¿Enseñanza de las matemáticas o matemáticas de la enseñanza? (Des)construcciones de planes de estudio para la formación inicial del professorado
}

\begin{abstract}
RESUMEN
A partir del tema "(Des)construcciones curriculares para la formación inicial de profesores que enseñan matemáticas: desafíos y escenarios de posibilidades para (re)existir", este texto pretende promover una reflexión sobre las posibilidades de (des)construcción de currículos para la formación inicial de profesores que enseñan matemáticas a partir de resultados históricos de investigación. Estos resultados nos muestran la importancia teórica de distinguir la "enseñanza de las matemáticas" y las "matemáticas de la enseñanza", en términos de enseñanza y formación de profesores. Con tal distinción y anclado en bases teóricas y metodológicas provenientes de la Historia Cultural, el estudio concluye que las posibilidades de (de)construcción curricular pasan por el cambio de naturaleza del conocimiento a socializar por el campo de la Educación Matemática, caracterizado por las matemáticas de la enseñanza.
\end{abstract}

Palabras clave: Matemáticas; Campo disciplinar; Enseñanza de las matemáticas; Educación Matemática; Epistemología.

\section{CONSIDERAÇÕES INICIAIS}

É prática dos campos disciplinares construir as suas formas elementares de modo a ser possível a sua transmissão para crianças e adolescentes. Em particular, o campo matemático, parece ser herdeiro dos estudos de Félix Klein. Desde, pelo menos, finais do século XIX, Klein irá sistematizar uma proposta de articulação, de ligação entre a matemática do ensino superior e aquela das escolas. O título de uma de suas obras é emblemático: “A matemática elementar de um ponto de vista superior” (KLEIN, 2009 [1908]. Assim, a matemática das escolas, como Klein se referia aos conteúdos que deveriam integrar os currículos não universitários, deveria constituir-se tendo em conta a matemática superior. Tratava-se de uma proposta reveladora de uma didática interna à própria matemática: a construção do elementar matemático a partir do que é superior. Borer (2017) nos auxilia a entender essa prática; diz autora, tratar-se do que pode ser entendido como a “ciência do conteúdo expressar a sua própria didática” (p. 190).

A criação, em âmbito internacional, na década de 1980, de um novo campo disciplinar que denominamos Educação Matemática, tendo nas suas fileiras de origem matemáticos, carrega consigo a mesma problemática enunciada por Klein: como articular um campo disciplinar e o ensino escolar? No entanto, o novo campo afastou-se da proposta de Klein, articulando-se às ciências da educação, em boa medida, à psicologia educacional, 
criando uma didática ou didáticas próprias. Porém, manteve o mesmo desafio: levar o campo disciplinar matemático ao ensino básico. Trata-se, pois, de uma questão essencialmente didática.

A manutenção da mesma problemática presente nos dois campos é motivo de enormes tensões entre os pesquisadores herdeiros de Klein, situados institucionalmente na SBM - Sociedade Brasileira de Matemática, e aqueles ligados à Educação Matemática, representados na SBEM - Sociedade Brasileira de Educação Matemática. Para além de questões de âmbito político, de disputa de poder, do ponto de vista da produção de novos conhecimentos, campos disciplinares distintos com mesmas problemáticas de pesquisa levam inevitavelmente a embates. A quem atribuir autoridade nas respostas diferentes dadas à mesma problemática? Há, em síntese, uma luta constante entre uma didática gerada internamente pela própria matemática e aquela que é fruto de diálogos com as ciências da educação. No entanto, do ponto de vista epistemológico, as duas perspectivas são convergentes: ambas reforçam a existência de uma matemática originária do campo disciplinar que deverá fazer-se escolar.

Este texto, com intuito de contribuir com o debate proposto pelo GT de Educação Matemática da ANPEd, tendo em vista a temática “(Des)construções curriculares para a formação inicial de professores que ensinam matemática: desafios e cenários de possibilidades para (re)existir", intenta promover uma reflexão sobre as possibilidades de (des)construção curricular para a formação inicial de professores que ensinam matemática a partir de resultados de pesquisas históricas ${ }^{2}$. Tais estudos levam-nos a distinguir "ensino de matemática" e "matemática do ensino".

\footnotetext{
2 Tais resultados vêm sendo obtidos pelo desenvolvimento de pesquisa financiada pela FAPESP, na linha "projeto temático", com período de desenvolvimento de seis anos (2017-2023), que reúne cerca de três dezenas de pesquisadores. Para maiores referências e detalhes sobre o projeto veja-se o endereço: https://bv.fapesp.br/pt/auxilios/98879/amatematica-na-formacao-de-professores-e-no-ensino-processos-e-dinamicas-de-producao-de-um-saber-pr/
} 


\section{Os campos disciplinares e a construção de retóricas sobre o ensino e a formação de professores}

Pierre Bourdieu, em texto publicado em 1975, deu contribuições fundamentais para a caracterização de um campo disciplinar científico. O texto teve reelaborações e ganhou sua forma final na publicação do livro "Science de la Science et réflexivité", publicado em 2001. $\mathrm{Na}$ obra, Bourdieu retomou a categoria de campo, segundo ele próprio, incorporando avanços teóricos e obtendo novas implicações que tal conceito pôde permitir.

Seguindo a exposição de Bourdieu, um primeiro elemento a mencionar indica que utilizar a noção de campo permite romper com pressupostos que são tacitamente aceitos pela maioria daqueles que se interessam pelas ciências. Assim, uma primeira ruptura implica desconsiderar a ideia de existência de uma ciência "pura", perfeitamente autônoma e desenvolvendo-se segundo sua lógica interna e, ainda, no seio de uma "comunidade científica" (BOURDIEU, 2001). Para o autor, "falar de campo, significa romper com a ideia de que os cientistas formam um grupo unificado, homogêneo" (2001, p. 91). Ainda, a ideia de campo subverte o pensar que o mundo científico é um lugar de trocas generosas, no qual todos os pesquisadores colaboram para o mesmo fim.

A noção de campo implica ter em conta de que há uma autonomia relativa dos grupos científicos considerados em relação ao universo social mais amplo. Isso significa, mais precisamente, que:

(...) o sistema de forças que são constitutivos da estrutura de um campo (tensão) é relativamente independente das forças que se exercem sobre o campo (pressão). Ele dispõe de todo modo da 'liberdade' necessária para desenvolver sua própria necessidade, sua própria lógica, seu próprio nomos (BOURDIEU, 2001, p. 95).

Ao considerarmos os estudos de Bourdieu, torna-se pouco fértil o uso de termos como "a ciência", "os cientistas", "os matemáticos", "a matemática", "o educador matemático" dentre outros. Interessa-nos, assim, ao invés disso, considerar "o campo disciplinar matemático", "o campo da Educação Matemática”, "as ciências da educação”, “o campo profissional da docência" e as relações que os indivíduos que participam desses campos compartilham entre si - as tensões, como diria Bourdieu; aquelas que os integrantes 
de um dado campo mantém com esse mesmo campo. Para além disso, importa o estudo, no tempo, das relações estabelecidas entre diferentes campos.

Em tempo mais recente, os estudos de Bourdieu sobre campos disciplinares foram retomados por Hofstetter; Schneuwly (2017), que sistematizaram as condições de estabelecimento de um campo disciplinar científico e suas disciplinas nos seguintes termos:

\begin{abstract}
-Uma disciplina emerge e se desdobra via a conquista de uma base institucional permitindo a profissionalização da pesquisa, que se concretiza pela institucionalização de postos, cadeiras, laboratórios, centros, garantindo a criação de um corpo de profissionais especializados no domínio.

-Esta base institucional favorece a constituição de redes de comunicação, tais como de associações de pesquisadores, de manifestações científicas (congressos, seminários etc.) e, sobretudo, de suportes editoriais (especialmente revistas) que permitem a construção de uma comunidade de cientistas trabalhando em torno das mesmas problemáticas.

-Esta infraestrutura institucional e comunicacional condiciona a renovação dos conhecimentos, instituindo o campo como empreendimento coletivo de pesquisa; esta produção de conhecimentos passa pela elaboração e aperfeiçoamento contínuo de conceitos e modelos teóricos, bem como das metodologias de coleta e análise de dados no domínio, respondendo aos critérios de legitimidade científica dos quais depende o reconhecimento social e científico da disciplina.

-Estas dimensões permitem uma socialização no campo e ela ocorre tanto mais facilmente quanto a disciplina se implanta como uma unidade de estreito imbricamento de ensino e pesquisa. Este desafio formativo está relacionado com aquele da capacidade de uma disciplina de determinar ela mesma os critérios de legitimidade de sua reprodução e de formar seus representantes (HOFSTETTER \& SCHNEUWLY, 2017, p. 23-24).
\end{abstract}

Sobre tais considerações haveria possibilidade de discutir vários temas importantes para a Educação Matemática como campo científico. De pronto, em termos dessa verdadeira grade avaliativa, enunciada pelos autores, sobre as condições de existência de um campo disciplinar e disciplinas científicas, tem-se a Educação Matemática atendendo a todos esses requisitos, instituindo-se como um campo disciplinar.

De outra parte, o que nos interessa mais especificamente para este texto diz respeito a atentarmos para o quesito citado em último lugar por Hofstetter; Schneuwly (2017): a necessidade de qualquer campo disciplinar promover a sua socialização em termos de ensino e pesquisa, visando a formação de seus futuros membros. Tal imperativo justifica o interesse dos campos disciplinares em escolarizarem-se. Não só os campos disciplinares precisam 
produzir novos saberes, a partir de suas problemáticas próprias de pesquisa, mas, para a sua própria sobrevivência e manutenção de seu status no âmbito social, necessitam estar presentes no meio escolar. Essa necessidade dos campos disciplinares não se expressa diretamente quando seus representantes tratam do ensino e da formação de professores. Ela é sempre encapsulada por uma retórica sobre o ensino e na formação de professores dada, por exemplo, por preocupações com o "nível de ensino", com o interesse na "atualização do ensino", com a ideia de que haja "rigor matemático no ensino", dentre outras expressões utilizadas pelos diversos campos, entre eles o campo disciplinar matemático, na construção de narrativas que justifiquem intervenções no meio escolar. Elas escondem, de fato, que o ensino e a formação de professores são elementos essenciais para a própria existência de um campo disciplinar.

No âmbito curricular, os campos disciplinares estão em constante disputa pela quantidade de aulas na programação escolar dos diferentes níveis de ensino. Quanto maior o status social conseguido por um campo disciplinar, maior tende a ser a sua presença na escola.

Sem adentrarmos pelas diferentes disciplinas e suas posições curriculares, a este texto interessa analisar, como já se disse antes, questões ligadas à matemática, tratadas em termos do campo disciplinar matemático e em termos do novo campo disciplinar que denominamos Educação Matemática. A análise tem em vista contribuir com reflexões sobre o currículo e com a mobilização de pesquisadores em torno de (des)construções de referências para o ensino e para a formação de professores. Para tal propósito, consideramos que a distinção entre "ensino de matemática" e "matemática do ensino" poderá, acreditamos, ajuntar elementos ao debate.

\section{ENSINO DE MATEMÁTICA}

Como dito anteriormente, o campo disciplinar matemático e a Educação Matemática, em termos de ensino e da formação de professores de matemática abordam a mesma problemática: como a matemática do campo disciplinar deverá ser escolarizada? Trata-se de 
investigar os mecanismos didáticos voltados para problemáticas postas pela transmissão de saberes dos campos disciplinares científicos para o interior do meio escolar.

Em termos do campo disciplinar matemático as respostas vêm sendo dadas tendo em vista as propostas de Félix Klein. O projeto Klein, em língua portuguesa, pode ser consultado no endereço: https://klein.sbm.org.br/.

Para além dessa proposta da SBM ser levada a professores, pesquisadores, pósgraduandos e graduandos, a defesa do ideário de Klein é divulgada também a público maior, por meio de matérias de jornal, escritas pelo atual diretor do IMPA - Instituto de Matemática Pura e Aplicada. Em tempo recente, Marcelo Viana, também colunista do jornal Folha de São Paulo, escreveu os artigos "Nossas escolas ensinam matemática do século 19" (22/12/2020) e "Que matemática ensinaremos e como?" (17/01/2021). Em ambos fez a apologia de que "o que Klein disse há mais de 100 anos atrás continua valendo hoje”.

No que se refere à formação de professores, o IMPA elaborou o "Programa Matemática na Escola”, sob a coordenação do professor Claudio Landim. Nos dizeres iniciais do documento definidor do Programa é possível ler: "O projeto se inspira no Programa OBMEP na Escola, implantado em 2016 em 900 escolas” (s/d, p.1). Assim, como meta desse Programa de formação continuada de professores tem-se: "Melhorar a nota de matemática no SAEB (antiga Prova Brasil), o IDEB da escola e a média na prova da segunda fase da OBMEP para as escolas com alunos no segundo segmento do Ensino Fundamental" (s/d, p.1). Nota-se, portanto, o vínculo direto entre a concepção de formação continuada de professores e os escores obtidos pelos alunos na Olimpíada de Matemática, carro-chefe orientador das ações de ensino e formação de professores do campo disciplinar matemático, representado pela SBM, ao meio escolar. Desse modo, o próprio campo disciplinar constrói suas diretivas de avaliação, promove certames e concursos sobre tais diretivas e intenta formar professores sob essa perspectiva disciplinar.

Em termos de pesquisas, considerando o novo campo da Educação Matemática - EM, a problemática do ensino de matemática nas escolas tem sido também parametrizada por imperativos do campo disciplinar matemático. Serão os estudos de Bachelard (1967) (1938), a partir de sua obra "A formação do espírito científico", uma das referências de base para o 
desenvolvimento das investigações na EM. Os pesquisadores voltados às relações entre campo disciplinar matemático e ensino acabaram por identificar, tendo em vista essa referência bachelardiana, os processos de avanço na produção científico-disciplinar, suas dificuldades e obstáculos com aqueles que se podem encontrar no ensino (SACHOT, 2006, p. 111-112). É desse modo que se pode entender os trabalhos de uma das figuras emblemáticas dos estudos sobre Didática da Matemática, Guy Brousseau, que a partir de 1976, constrói de modo sofisticado, uma marcha de ensino considerada científica, uma Didática como campo científico, tomando emprestado o conceito de obstáculo epistemológico de Bachelard (ARTIGUE, 2008, p. 159). Assim, na construção da marcha do ensino, do seu passo-a-passo, nas sequências didáticas, há que serem investigados os obstáculos epistemológicos, de modo a serem construídas etapas, graduação do ensino, de maneira a que não sejam criadas dificuldades para o progresso dos alunos ao nível superior matemático.

Por certo a EM reúne várias perspectivas teórico-metodológicas. De outra parte, cabe reconhecer que a chamada "Didática francesa" exerceu e ainda exerce papel fundamental na constituição desse novo campo.

De um modo ou de outro, ter como problemática o ensino de matemática revela-se como o desafio de estabelecer a passagem do campo disciplinar matemático para o meio escolar. Em última análise, está posta como premissa que o papel da escola é o da transmissão dos saberes do campo disciplinar. Neste caso, do campo disciplinar matemático. Por certo, nessa perspectiva - a do ensino de matemática - a matemática do campo disciplinar não é considerada idêntica àquela presente no meio escolar. Mas, as diferenças evocadas levam em conta tão somente aspectos de sua didatização. Cabe a tarefa de organização do saber matemático, em seus elementos, para que possa ser transmitido aos alunos. Dessa maneira, as diferenças que se estabelecem entre a matemática do campo disciplinar e aquela a ser transmitida na escola são consideradas em termos de nível: de uma matemática mais avançada do ensino superior àquela elementar da escola básica. E caberá à pedagogia ocupar-se da tarefa de tornar possível o ensino. Nesse caso, bem adequada é a crítica que Chervel (1988) realiza indicando que o desafio do campo disciplinar para ser transmitido lança mão de ideia redutora da pedagogia: ela é vista como elemento lubrificante a permitir que, na escola, seja possível a transmissão dos saberes dos campos disciplinares científicos. 


\section{MATEMÁTICA DO ENSINO}

Em linhas anteriores buscou-se demonstrar, em primeiro lugar, que tanto o campo disciplinar matemático como a Educação Matemática, têm a mesma problemática de pesquisa relativamente ao ensino e à formação de professores. Para além disso, mesmo que por meio de construções de didáticas próprias, a Educação Matemática, afastando de uma didática interna, de uma didática gerada pelo próprio conteúdo a ser ensinado, própria dos seguidores de Klein, apresenta convergências relativamente ao saber de referência a ser transmitido. Ambos os campos tomam a matemática superior como referência para a construção de didáticas que levem tal saber ao meio escolar, à cultura escolar. Em termos mais técnicos, a mesma problemática de pesquisa para esses dois campos, leva ao mesmo caminho para resposta: elaborar o elementar matemático de modo a que haja continuidade dos estudos da escola básica até o nível superior. Por certo, como se disse, se há convergência sobre ter-se o campo disciplinar matemático lugar de referência para o ensino, as propostas didáticas são diferentes. Também como se viu, o campo matemático elabora uma proposta própria, interna a esse saber, herdeira de Klein. Já a Educação Matemática, nas suas relações como o campo das ciências da educação, formula alternativas, engenharias, sequências, transposições de modo a erigir uma didática própria ao campo. E é emblemático que, na França, lugar de origem de boa parte dos estudos da Educação Matemática, o novo campo seja por lá denominado "Didática da Matemática”.

Diferentemente da perspectiva que chamamos "ensino de matemática", que alinha dois campos de pesquisa diferentes, como a Matemática e a Educação Matemática, a "matemática do ensino" apoia-se em estudos elaborados em igual época da construção do campo da Educação Matemática. Tais referências vêm desde finais da década de 1980, com os estudos de André Chervel, em termos da caracterização que esse autor fez do que denominou "disciplinas escolares". Com esse constructo teórico e alicerçado em estudos históricos sobre a gramática da língua francesa, Chervel mostrou que os saberes escolares têm autonomia face aos campos disciplinares. Assim, o autor promoveu uma verdadeira ruptura epistemológica relativamente à concepção vigente de que os saberes escolares representariam formas elementares dos saberes dos campos disciplinares científicos, tratados por meio de uma pedagogia lubrificante, como se mencionou em linhas acima, ou de 
didáticas específicas. E, poderíamos acrescentar, especificando: esses saberes escolares também não constituiriam formas lubrificadas por uma didática da matemática aplicadas ao campo disciplinar matemático.

A perspectiva de Chervel (1988), nos parece, foi aprofundada por historiadores como Dominique Julia. Este autor, relativizou um tanto as afirmações categóricas de Chervel, demonstrando que se há uma autonomia dos saberes escolares, ela é uma autonomia relativa, em termos dos embates que a cultura escolar tem com outras culturas para a produção de saberes, inclusive com as culturas acadêmicas, lugar dos campos disciplinares (JULIA, 2001). E, ainda, por meio dos estudos de Julia tem sido possível alargar o conceito de cultura escolar, considerando-o como o espaço descontínuo que envolve a formação para o ensino e o ensino propriamente dito.

Se para a perspectiva do "ensino de matemática" o desafio colocado é eminentemente didático: como levar a matemática do campo disciplinar às escolas? Sob a perspectiva de autores como André Chervel e Dominique Julia, e considerando o caso específico da matemática, a questão passou a ter caráter epistemológico: como é elaborada uma matemática para o ensino e para a formação de professores? Tal pergunta para ser respondida coloca o desafio de um deslocamento: transladar-se do campo disciplinar matemático e postar-se no âmbito da cultura escolar, entendida como espaço descontínuo que reúne o meio escolar, a cultura escolar. Assim, precisando melhor a questão, interroga-se: como a cultura escolar produz uma matemática para o ensino e para a formação de professores? Do mesmo modo que fez Chervel, o entendimento do processo de elaboração de saberes no âmbito da cultura escolar leva-nos a estudos históricos. Investigações sob essa perspectiva, que pode nos dar resposta à questão, vêm sendo desenvolvidas nos últimos anos. Tais estudos, atentos a determinadas épocas do ensino, mostraram, com a mobilização de fontes empíricas ligadas à cultura escolar, tais como livros didáticos e manuais pedagógicos, como foi elaborada uma "aritmética intuitiva" (OLIVEIRA, 2017); ou como em tempos da emergência da pedagógica cientifica construiu-se uma "aritmética sob medida" (PINHEIRO, 2017); ou, ainda, como foi elaborada uma aritmética para a formação de professores de modo a que pudessem ensinar uma "aritmética intuitiva" (MACIEL, 2019); também, como foi construída uma geometria própria a ser mobilizada pelo professor de modo a ensinar geometria em tempos do método intuitivo (FORTALEZA, 2020). 
Esses resultados de pesquisas elaboradas no âmbito da História da educação matemática levam-nos à caracterização de uma “matemática do ensino", elaborada historicamente, no âmbito da cultura escolar, envolvendo tanto o ensino como a formação de professores.

\section{CONSIDERAÇÕES FINAIS}

Chegados a este ponto, admitida como hipótese de trabalho teórico, a existência de uma "matemática do ensino", retoma-se o imperativo que há para um campo disciplinar buscar a sua socialização em termos de ensino e formação de professores. Trata-se, como se mencionou anteriormente, da Educação Matemática vencer o desafio de "uma disciplina de determinar ela mesma os critérios de legitimidade de sua reprodução e de formar seus representantes" (HOFSTETTER \& SCHNEUWLY, 2017, p. 24).

Tal empreitada coloca, de pronto, a questão: qual saber o campo da Educação Matemática deverá levar às escolas, de modo a referenciar o ensino e, ainda, a formação de professores? Por certo, se tal interrogação for formulada ao campo disciplinar matemático, sua resposta será imediata: a matemática. De outra parte, se a Educação Matemática tiver a mesma resposta, perpetuam-se os embates, com enorme vantagem para o campo disciplinar matemático, detentor único do status social de produção desse saber, do saber matemático. Há que promover a (des)construção curricular.

Os estudos históricos que, por sua própria natureza, têm por finalidade a análise e compreensão das mudanças ao longo do tempo, poderão contribuir para dar resposta a essa questão aparentemente sem solução, posta à Educação Matemática, em termos de sua consolidação como campo de pesquisa. Tais estudos vêm demonstrando que, historicamente, têm sido construídos novos saberes, novas matemáticas para o ensino e também para a formação de professores, no âmbito da cultura escolar, agora com a mudança paulatina dos formadores, egressos da Educação Matemática, que aos poucos tornam-se vetores de institucionalização de novas disciplinas formadoras de professores ou mesmo reconfigurações de antigas disciplinas que permanecem nas grades curriculares dos cursos de pedagogia e de licenciatura em matemática. Como exemplos, tem-se os estudos de 
Magalhães (2013) e Valente (2014) relativamente à rubrica "Prática de Ensino"; e, ainda, os estudos de Grotti (2019) e Valente \& Grotti (2020) sobre o "Cálculo Diferencial e Integral”.

Esse movimento de investigação que toma a cultura escolar como referência para estudos sobre o ensino e a formação de professores na atualidade parece já ter começado e tem iluminado pesquisas em tempos mais recentes. Internacionalmente é possível citar documentos como as orientações canadenses publicadas desde 2001 (MARTINET et al., 2001). Esperemos que perspectivas dessa natureza, para além de produzirem um deslocamento do lugar de investigação dos pesquisadores da Educação Matemática, favoreçam a elaboração de problemáticas próprias a esse campo relativamente recente.

Por fim, caberia dizer que a (des)construção curricular, por certo, não deverá promover uma volta às origens, da reafirmação do campo disciplinar, embatendo-se com a pedagogia das competências. O horizonte das mudanças leva-nos às alterações que já vêm ocorrendo com a produção de novos saberes para o ensino e para a formação de professores, novas matemáticas, matemáticas do ensino.

\section{AGRADECIMENTOS}

O presente trabalho foi realizado com apoio da FAPESP - Fundação de Amparo à Pesquisa do Estado de São Paulo.

\section{REFERÊNCIAS}

ARTIGUE, M. Continu, discontinu em mathématiques. Quelles perceptions en ont les élèves et les étudiants? In: VIENNOT, L. Didactique, Épistémologie et Histoire des Sciences. Paris: PUF, 2008.

BACHELARD, G. La formation de l'esprit scientifique. Paris: Vrin, 1967 (1938).

BORER, V. L. Saberes: uma questão crucial para a institucionalização da formação de professores. IN: HOFSTETTER, Rita; VALENTE, Wagner Rodrigues. Saberes em (trans)formação: tema central da formação de professores. São Paulo: L F Editorial, 2017, p. 173-200. 
BOURDIEU, P. Science de la science et réflexivité. Cours du Collège de France. Paris: Raisons d'Agir Éditions, 2001.

CHERVEL, A. L'histoire des disciplines scolaires - Réflexions sur um domaine de recherche. Histoire de l'éducation. Paris: SHE, N. 38, mai., 1988.

GROTTI, R. O Cálculo Diferencial e Integral para Ensinar: A Matemática para a Licenciatura em Matemática. Tese (Doutorado em Educação em Ciências e Matemática) UFMT/UFPA/UEA - PPGECEM/REAMEC, Cuiabá/MT, 2019.

HOFSTETTER, R.; SCHNEUWLY, B. Disciplinarização e disciplinação: as ciências da educação e as didáticas das disciplinas sob análise. In: HOFSTETTER, Rita., \& VALENTE, Wagner Rodrigues. (Orgs.). Saberes em (trans) formação: tema central da formação de professores. $1^{\mathrm{a}}$ ed. Editora Livraria da Física, (Coleção Contextos da Ciência), São Paulo, 2017, p. 21-54.

JULIA, D. A cultura escolar como objeto histórico. Revista Brasileira de História da Educação, n. 1, Jan./Jun., 2001.

KLEIN, F. A matemática elementar de um ponto de vista superior. Volume 1. Parte 1. Aritmética. Lisboa: SPM, 2009 (1908).

LANDIM, C. Matemática na Escola - IMPA, s/d.

MACIEL, V. Elementos do saber profissional do professor que ensina matemática: uma aritmética para ensinar nos manuais pedagógicos (1880-1920). Tese (Doutorado em Ciências). Universidade Federal de São Paulo, São Paulo, 2019. Acesso em: https://repositorio.ufsc.br/handle/123456789/199390

MAGALHÃES, F. T. Memórias de práticas: a disciplina 'Prática de Ensinona formação do professor de matemática. Dissertação (Mestrado em Mestrado Profissional em Educação Matemática) - Universidade Federal de Juiz de Fora, 2013. Disponível em: https://www2.ufjf.br/mestradoedumat/wpcontent/uploads/sites/134/2011/05/Disserta\%C3 \%A7\%C3\%A3o-Fernanda-Luciana.pdf Acesso: 16/06/21.

MARTINET, M. A. et al. La formation à l'enseignement - les orientations, les compétences professionnelles. Gouvernement du Québec. Ministère de l'Éducation, 2001.

OLIVEIRA, M. A. A aritmética escolar e o método intuitivo: um novo saber para o curso primário (1870-1920). Tese (Doutorado em Ciências). Universidade Federal de São Paulo, São Paulo, 2017. Acesso em: https://www.repositorio.unifesp.br/handle/11600/50818

PINHEIRO, N. V. L. A aritmética sob medida: a matemática em tempos de pedagogia científica. Tese (Doutorado em Ciências). Universidade Federal de São Paulo, São Paulo, 2017. Acesso em: https://repositorio.ufsc.br/handle/123456789/179942 
SACHOT, M. Les disciplines scolaires, les modèles et les contre-modèles des curriculums de formation professionnelle. In: LENOIR, Y.; BOULLIER-OUDOT, M. H. Savoirs professionnels et curriculum de formation. Québec: Les Presses de l'Université Laval, 2006.

VALENTE, W. R. A Prática de Ensino de Matemática e o impacto de um novo campo de pesquisas: a Educação Matemática. Alexandria, v. 7, n.2, 2014. Disponível em: file:///Users/wagnervalente/Downloads/DialnetAPraticaDeEnsinoDeMatematicaEOImpactoDeUmNovoCampo-6170849\%20(1).pdf . Acesso: 16/06/21.

VALENTE, W. R.; GROTTI, R. A Educação Matemática e a emergência de um novo Cálculo Diferencial e Integral para a Licenciatura em Matemática. RECME, V. 5, N. 1, 2020. 